\title{
Outorgado o Título de Professor Honorário ao Dr. Francisco Cavalcanti Pontes de Miranda.
}

Em solenidade realizada a 14 de dezembro de 1966, no salão nobre desta Faculdade, foi outorgado pela Congregação dos Professôres o título de "Professor Honorário" a ilustre jurista brasileiro, Francisco Cavalcanti Pontes de Miranda.

Aberta a sessão pelo Sr. Diretor, Prof. Dr. Alfredo Buzaid, foi o homenageado introduzido no recinto, recebendo a saudação dos professôres através expressivas palavras do Dr. Canuto Mendes de Almeida, transcritas a seguir.

Discurso de Saudação do Prof. Dr. Canuto Mendes de Almeida.

A glória de saudar Pontes de Miranda, em nome da Congregação da Faculdade de Direito, vem acompanhada de júbilo do amigo, que, durante quatro decênios, recebeu do mestre, através de seus livros, e de suas incitações à reflexão jurídica, o melhor estímulo ao estudo do Direito, e à veneração da Liberdade e da Democracia. Grato sou, pois, com reverência, aos que me galardoam, e especialmente ao professor Alfredo Buzaid, deferindo-me a prerrogativa do intérprete, hoje e aqui, dos mestres das Arcadas. Eles há muito tempo (alguns dos quais sempre 
ressurgem na nossa lembrança) sentiam, em si próprios, o dever de convocar, para ser um dos nossos, àquele que, sem dúvida, no transcurso de mais de meio século de infatigável labor, conseguiu projetar, nos altos meios culturais do pais e no estrangeiro, um sublime nome de jurista excelso, e o prestígio do Brasil, como país de superior e secular formação jurídica.

Ajunta-se, agora, Francisco Cavalcanti Pontes de Miranda àquela constelação de luminares, que, em vida, integraram o quadro de honra refulgente da vetusta Academia de Direito: Ruy Barbosa, Clovis Bevilacqua e Mendes Pimentel.

Seria impertinente biografar o alagoano, nascido em 1892, cujos pendores pela ciência dos números logo lhe nasceram do pai, Joaquim Pontes de Miranda, bacharel (que cursara os primeiros anos de Direito neste Largo de S. Francisco), mas também e principalmente professor de matemática, e cujas inclinações filosóficas viriam a despontar na convivência franciscana, quando, para aprender alemão, hospedou-se, estudante, no Convento de São Francisco, no Recife, e acabou empenhado em sistematizar sua própria orientação metafísica. Fê-lo ao influxo de monges - conta Pontes de Miranda - frades que tanto haviam influído na formação jurídico-política da Inglaterra, criando Oxford, na de Portugal, instaurando a Universidade de Lisboa, na Áustria, e na de muitos outros países, que bem souberam absorver, em mais instituições, as repercursões racionais da teoria e da prática da bondade do Santo de Assis.

Seria impertinente, repito, - tratando-se de Pontes de Miranda, notória personalidade - desfiar, nesta sessão solene, o esplendoroso e ressabido relato da vida do moço que, antes dos 19 anos, bacharelando-se em Pernambuco, já escrevera seu primeiro trabalho, A Margem do Direito; e, aos 22 anos, A Sabedoria dos Instintos; que, pouco de- 
pois, merecia o "Prêmio Pedro Lessa", de erudição, por seu livro Introduçâa à Sociologia Geral, no qual, por primeiro, se falou de espaço social e de dimensões sociais, constituídas pelos processos sociais de adaptação; que, em 1922, verteu para o alemão o então recente Código Civil brasileiro, com anotações; que, por sugestão de Josef kohler e Fritz T. Z. Berotzheimer, fêz-se colaborador de revistas de Direito alemãs.

Também não caberia, desta tribuna, repetir que, em 1923, Pontes de Miranda, aferrado sempre à marca matemática da infância, divergiu da teoria do espaço de Einstein, a quem escreveu. O sábio sugeriu-lhe que desenvolvesse o assunto e o remetesse ao Congresso Internacional de Filosofia, de Nápoles, 1924, do qual não veio a participar qualquer representante do Brasil. Atendeu o bacharel à sugestão. Sua comunicação, foi aprovada pelos congressistas, inclusive por Einstein e Max Plank, como consta das Atti del Congresso Internazionale de Filosofia, publicado em 1925.

Tal êxito é que explica sua presença, em seguida, na Casa Wilhelm Stiftung, em Berlim, para discorrer sôbre tema de Direito Internacional. A conclusão - "E cedo, no mundo dividido, para codificar-se o Direito das Gentes" repercutiu, devido, sobretudo, à presença de Max Plank e ao discurso de Martin Wolff, e, ainda, aos comentários de Heymann, numa revista, o qual disse que Pontes de Miranda, como jurista, só se explicava pelo matemático o filósofo que nele havia.

Impertinente, pois, seria biografar, aqui, o homenageado. Prefira-se, pois, qualificar sua obra.

Duas notas essenciais nela predominam: o marcado sêlo de Pontes de Miranda pela liberdade, a levá-lo à ênfase que dá, invariàvelmente, em seus livros, ao trato dos direitos fundamentais, prerrogativas indeclináveis da pessoa humana, a sobrancearem todos os demais aspectos 
juridicos da vida; e seu menos patriótico do que justo afã de demonstrar que, aos ensinamentos peregrinos, se hão de juntar os de nossa gente antiga, de ultramar, os velhos reinícolas, e os de alguns de nossos antigos e modernos juristas brasileiros. Nessa ordem de considerações, chama a atenção dos estudiosos do direito pátrio, para a sedimentada sabedoria de juristas que já sabiam e já diziam, bem melhor do que certas atuais celebridades, coisas até que se apresentam como originais, importadas de velhos empórios da cultura ocidental, conceitos arquitetados e armazenados alhures, onde não raro menos há o que ensinar aos brasileiros do que aprender no direito brasileiro.

Afaste-se, porém, de quem o saúda, eminente Pontes de Miranda, professor honorário da Faculdade de Direito da Universidade de S. Paulo, o aparente espírito de ridículo xenofobismo, ou estulta pretensão de toldar ostensivos méritos de grandes lidadores da filosofia e da sociologia do direito dos últimos séculos e de vigorosos inspiradores da jurisprudência, como ciência. Êsses, pelo valor de suas sistematizações, pela energia do pensamento e pela lógica de ideais, lograram inserir-se no quadro ecumênico, superando os acanhados âmbitos regionais, como juristas de tôdas as Nações e como mediatos artífices do progresso das instituições de tôdas as nacionalidades. Afaste-se do orador, sobretudo, o propósito - que seria injurioso de imputar ao homenageado vesgo nacionalismo, e descabido, tanto mais afrontoso quanto Pontes de Miranda, tão aferrado àquele afã de render justiça aos ancestrais lusos, enriquece a galeria de intelectuais que timbram por mostrar a incindivel continuidade entre o provincial e o nacional, entre o nacional e o internacional, numa escala hierárquica de valores, na qual, econômicamente e socialmente, cada vez mais, o universal condiciona o geral, e o geral condiciona o particular, em movimento dialético de ascenção, para a unidade do mundo e a igualdade dos sêres humanos. Segundo Pontes de Miranda, as nações de hoje, como os feudos de ontem, ou as cidades da antigüi- 
dade, bem como até mesmo os grandes do imperialismo contemporâneo, (que, contrapostos, forjam etapas da juncão final, embora por surpreendentes caminhos contradifórios: coisas que só sabe explicar a caprichosa psicologia política da humanidade), cada país vive política e juridicamente na medida qualitativa e quantitativa do que lhe permitem os demais paises, mesmo os mais fracos, ao sabor das resultantes de fôrças interestatais e supraestatais, dentro de uma conjuntura econômica, que, sociològicamente, gera os resultados históricos.

Por isso, seus Comentários às nossas Constituições de 1934, de 1937 e de 1946, e suas outras obras de Direito Constitucional, de Teoria Greral do Estado, de Filosofia Política ou de Ciência Política, mostram, fundamentalmente, como as Constituições de cada nação participam de uma como que Constituição maior, universal, implícita, de que tôdas são sorte de diplomas tributários, ramificação, mas em vias de se tornar explícita, através da cristalização crescente das normas superiores e dos pressupostos da Organização das Nações Unidas.

Ilustre professor de Direito, em saudação a V. Exa., recente, em Pôrto Alegre, frisou, com justiça, que Pontes de Miranda - que tanto presa a ciência lusa - é, entre nós, o representante máximo daquele movimento de idéias desencadeadas por Tobias Barreto, no século passado, sob inspiração do pensamento jurídico germânico.

E não é só!

Quem - nos arraiais do direito público e, especialmente, do constitucionalismo - ousaria ignorar quanto Pontes de Miranda (em suas obras de implicação política, como História e Prática do Habeas Corpus, como os Comentários às Constituições, como seus livros Democracia, Liberdade e Igualdade, Os Novos Direitos do Homem, Direito d̀ Subsistência e Direito ao Trabalho, Direito à Educação e Anarquismo, Comunismo e Socialismo) foca- 
liza a marcada influência dos ideais da independência americana e da revolução francesa e da longa evolução jurídico-política inglêsa, exercida sôbre as instituições básicas do Brasil Império e do Brasil República? e, ainda, sôbre a sistematização das garantias dos direitos individuais na normação de nosso direito processual penal?

O grande mérito de quem sabe conciliar o particular com o geral, ou melhor, no tema em foco, o sistema jurídico tradicional brasileiro, de traves principais, reinícolas, com os benéficos influxos da civilização universal, está em poder demonstrar, como soem adaptar as virtudes da tradição, que o Brasil não abandona, com os caminhos ascencionais do progresso humano, na ordem civil e política, na ordem social e econômica.

Dada a feição polimorfa de sua inteligência e de sua cultura, Pontes de Miranda, em suma, sabe prezar os Mendes de Castro, Valasco, Gama, Febo, Reinoso, Pedro Barbosa, Arouca, Souza de Macedo, Aires do Pinhal, Pêgas, Vanguerve, ou Alexandre Caetano Gomes e Matheus Homem Leitão, e Paiva e Pena, e Diogo Camacho de Aboim Guerreiro, e, ainda os mais recentes, Joaquim José Caetano Pereira e Souza e Manuel de Almeida e Souza. Sabe prezá-los - sim - a êsses e outros velhos autores, afeiçoando-lhes entretanto, os ensinamentos à renovação do pensamento jurídico ocidental e, universal!

No âmbito da processualística, Pontes de Miranda não vê razão para que os descobrimentos de Bülow, sôbre a teoria dos pressupostos processuais, ou as doutrinas de Kohler, Degenkolb ou A. Plosz, ou a polêmica entre Windscheid e Mutter, ou as afirmações de Helwig, James Goldschmidt, Beling ou Binding, ou o justo prestígio de Calamandrei, Chiovenda ou Carnelutti, devam ou possam obscurecer os lâmpejos de genialidade emergentes daqueles ensinamentos de antanho.

O mencionado professor gaúcho, abordando a transplantação para o Brasil do conceito de "Tatbestand" por 
(bra de Pontes de Miranda, adverte: "Dos autores mais antigos aos mais recentes, os juristas alemães de maior prestígio na Ciência esqueceram de examinar o plano da existência. Para êles há apenas a relação TatbestandRechtsfolge, suporte fático e efeito jurídico" (razão pela qual os atos nulos, via de regra - afirma o mesmo colega de Pôrto Alegre - são considerados inexistentes, pelos melhores juristas alemães). Pois bem! A Pontes de Miranda deve-se não apenas aquela transplantação do conceito de "Tatbestand", ou sua pura inserção no sistema do pensamento jurídico brasileiro, como fôra importado, mas também - o que constitui sua grande contribuição à ciência do direito - o plano da existência, "fundamental (observa aquêle professor), tanto quanto o da validade e o da eficácia, para compreensão e qualificação científica dos fatos juridicos". Trata-se de uma "original descoberta no centro mesmo da teoria geral do direito" Os precursores - e houve - jamais tinham teorizado o tema. Nenhum dêles traçou-lhe os limites.

Também é Pontes de Miranda original: na análise e complementação científica do plano da eficácia; no exame profundo da ação em sentido material, com a coisa distinta da pretensão; e na diferenciação mais exata entre ato, em sentido estrito, e ato-fato, motivo de graves confusões. ainda hoje, entre juristas alemães.

Oração de Agradecimento do Professor Honorário Francisco Cavalcanti Pontes de Miranda.

Após à saudação do Prof. Dr. Canuto Mendes de Almeida, o novo professor honorário proferiu a seguinte oração de agradecimento:

"Quando, há quarenta anos, no Rio de Janeiro, por proposta de Manuel Inácio Carvalho de Mendonça, Francisco de Paula Lacerda de Almeida, Irineu Machado, Afonso 
Celso e outros professôres, a Faculdade de Direito me conferiu o título de Professor Honorário, recebi aquela honra como incentivo para a minha vida de jurista.

"Hoje, diante de vós, que me destes o mesmo título, eu o recebo, depois de outros que tive, com alegria especial, profunda, não só por partir de quem partiu, como porque a notícia vibrou em minha consciência, como se tivésseis julgado a minha vida dedicada ao direito. $O$ que pude fazer, ilustres professôres e amigos, fiz. Na vida nunca eu quis destruir, sòmente construí ou tentei construir. Não poupei qualquer esfôrço. Não medi qualquer sacrifício. E recebo o título que a casa do Largo de São Francisco me entrega, com emoção, porque é, para mim, como a aprovação do pertinaz estudante de direito, assíduo e convicto, durante sessenta anos. De mais de meio século é o tempo de minha atividade de escritor de direito e de sociologia.

"Porquê, perguntareis, tal insistência, tanta dedicação? Porque cedo cheguei à convicção de que as civilizações mais dependem do Direito do que dos outros processos sociais de adaptação. E o Direito que as estrutura, sem as peiar e sem as empurrar para abismos. Se tanto quis e quero contribuir para o Direito foi e é porque me convenci de que a nossa civilização sòmente se pode conservar, se mantemos a tradição jurídica, alterando-a quando estivermos persuadidos de que é preciso que se altere. Nesse meio século vimos bem que os atos violentos dos que a exploram, dizendo que a defendem, em tantos paises do Mundo, ou a puseram em perigo, ou a destruíram.

"Para se criar ou se chegar à estabilidade, que permita a evolução social, é preciso que diante de cada sociedade ou grupo de sociedades se conheçam os pesos dos processos sociais de adaptação e se verifique, na espécie, o que é que se passa. A Religião é o que mais estabiliza. Depois, a Moral e a Arte. O processo social de adaptação mais instável é a Economia; depois, a Política e o Direito. 
A Ciência não instabiliza, nem estabiliza: ela sòmente contém enunciados de fato, "é" ou "não é". Em regiões asiáticas e africanas onde as populações ficaram frenadas pela Religião, o caminho que se tem para as trazer ao nosso tempo é o de aumentarmos o coeficiente de Economia, de Política e de Direito, servindo-nos do exemplo de outros povos e da Ciência. Se há uma guerra, como a de 1914, em que os Estados em luta não arrebentam o seu Direito interno, é possivel que se passe da monarquia para a república, sem que se destrua a estrutura social. Se há guerra como a que fizeram Estados que empregaram, antes, a violência dentro dos seus limites, a estrutura social é atingida.

"O Direito é que pode diminuir a instabilidade que se origina da Economia e da Política. Hoje em dia não basta o que há de Religião, de Moral e de Arte nas sociedardes que correspondem ao século XIX ou ao século XX. A Ciência introduz-se em cada uma, porém a Ciência não estabiliza, nem instabiliza.

"Depois que se soube qual o pêso de quanto despótico, de fôrça, que há nos processos sociais de adaptação, pode-se cuidar da vida social como problema de ciência. O mais violento é a Política, digamos 7; depois, a Economia, digamos 6; depois, a Religião, digamos 5; o Direito, digamos 4; a Moral, digamos 3; a Arte, digamos 2; a Ciência, digamos 1 .

"Em tudo isso assenta a minha convicção da importância que tem o Direito. Não era a de que, até os quatorze anos, queria dedicar-me. Em 1907, nas vésperas de embarcar para a Europa, a fim de estudar Matemáticas e Física em Oxford (meu avô paterno e meu pai eram matemáticos e bacharéis em direito), uma tia, Dona Francisca Meneses, convenceu-me de que eu devia estudar Direito e ao Direito dedicar-me. Ela queria que eu viesse para São Paulo e lia-me cartas de Albuquerque Lins. O 
marido falecera antes de vir tomar posse da Presidência da Província de São Paulo e o secretário dêle, que aqui permanecia, acabou - como há revelações surpreendentes nos destinos humanos! - Presidente do Estado de São Paulo. Albuquerque Lins, como Francisco Meneses e como eu, era alagoano. Em São Paulo, dizia êle "mais se ama o Direito do que em todo o Mundo". A que se deve isso? A Faculdade de Direito das Arcadas. Era o que também pensava meu avô paterno que aqui estudou alguns anos e fôra deputado da Assembléia Constituinte da República.

“Não vim para São Paulo; formei-me no Recife, onde também sou professor honorário. Mas sempre tive atração profunda por São Paulo e pelo Rio Grande do Sul, que teve filhos responsáveis por 1930 e 1937, porém não foi responsável, porque o Rio Grande do Sul aprendeu a amar o Direito com São Paulo e com o Recife.

"Quando se lê a lista dos que se formaram na Faculdade de Direito de São Paulo, no Império e na República, tem-se a certeza de que a Faculdade de Direito das Arcadas foi a caixa de tintas e de pincéis com que se pintaram dois terços ou mais da história do Império e da República.

"Na Minha biblioteca, a grande maioria dos livros de direito, em língua portuguêsa, foram escritos por professôres daqui, ou por antigos estudantes, de outros lugares do país, que aqui se formaram. A Faculdade de Direito das Arcadas foi e é - com os Gama e Silva, os Alfredos Buzaid e tantos outros luminares aqui presentes - a capital brasileira do Direito. Daí temos de esperar que São Paulo e o Rio Grande do Sul nos dêem a oportunidade de voltarmos à segurança jurídica. Em 1922, publiquei numa revista alemã artigo sôbre Segurança Jurídica $e$ Ordem Intrínseca. Mostrava a necessidade da segurança jurídica para que haja evolução das indústrias e inversão honesta de capitais. Onde não há segurança jurídica, não entram capitais e muitos capitais saem. A relevância do Direito comprova-se a cada momento. 
"É acertado e necessário que o homem se dedique às ciências, é necessário que se prossiga nas investigações e se aumente o número de descobertas. Mas isso só é possivel com a estabilidade jurídica. Para se saber se alguma regra jurídica é boa, ou se é apenas tolerável, ou se é ruim, temos de procurar descobrir-lhe as conseqüências, e às vêzes basta contribuirmos para esclarecimento que lhe dê mais fácil e mais adequada aplicação.

"Nas Constituições, quando se fala em Deus, ou, por exemplo, em casamento indissolúvel, há dificuldade de alteração. Nos princípios constitucionais em que se diz que todos são iguais perante a lei, o elemento ético introduziu-se. Não é fácil mudar-se o princípio. Mas onde o conteúdo é econômico ou politico, só as regras constitucionais limitativas do poder de emenda podem salvar da violência e da instabilidade da Economia e da Política, principalmente dessa.

“A lei, como qualquer outra regra jurídica, é o que um, dois ou mais processos sociais de adaptação propõem ao processo social político para que, levando-a ao Direito, êsse lhe dê mais estabilidade do que teria na dimensão só política.

"A técnica legislativa constitucional da divisão dos poderes tem por fito evitar que os que subiram ao poder, sem serem pessoas que o merecessem, não possam fazer o mal. Os que o merecem conseguem o bem dentro dos poucos poderes. Quando, na história se quebra o equilíbrio dos poderes, volta-se a momentos remotos, talvez à iribus e a cavernas.

"Temos de elevar o nível cultural do Brasil e a São Paulo cabe a maior parcela de tão grande missão. Temos de colaborar na própria conquista dos outros planetas.

"Porém não nos esqueçamos que há ciência da sociedade e do homem, que os processos sociais de adaptação, conforme os coeficientes que se encontram em cada um 
de nós, nos diferenciam e nos marcam. Hoje se mede o que a sociedade deposita no homem e não só aquilo com que o homem concorre para o corpo social.

“A Faculdade de Direito de São Paulo fêz grandes juristas e os grandes economistas do Império e da República. Continua com a sua missão.

"Ilustres Professôres! Há quarenta anos fiz a primeira conferência na Faculdade de Direito das Arcadas. Saudou-me o Professor Vicente Ráo, grande jurista, cuja amizade encareço. Pelos estudantes, conforme os Estados, falaram, por São Paulo, o ilustre professor Joaquim Canuto Mendes de Almeida, orador desta noite, Dario de Almeida Magalhães, por Minas Gerais, Marcelio de Queirós, que faleceu quando Desembargador do Tribunal de Justiça do Distrito Federal. Depois, dei cursos rápidos e fiz-me amigo de pessoas ilustres como o Professor Alfredo $\mathrm{Bu}$ zaid, o Professor Miguel Reale, o Professor Luis Eulalio de Bueno Vidigal, o Professor José Carlos de Ataliba Nogueira e o Professor Goffredo da Silva Telles Júnior. O nível do professorado de São Paulo é alto e de vós, que tanto colaborastes para a grandeza jurídica do Brasil, muito ainda esperamos. O Brasil precisa, mais do que nunca, da Faculdade de Direito das Arcadas. Tenhamos esperança em que em 1967 se abram estradas novas, larguíssimas, para os nossos Bandeirantes do Brasil, Bandeirantes de todo o Brasil, com os focos, bem acesos iluminantes, do Direito. 